\title{
Vegetation root system, soil erosion and ecohydrology system: A review
}

\author{
Bing Liu ${ }^{1, a^{*}}$, Gang Xie ${ }^{1, b}$, Xiaoming Zhang ${ }^{1, c}$, Yang Zhao ${ }^{1, d}$, Xiaolin Yin ${ }^{1, e}$, Chen \\ Cheng ${ }^{1, f}$ \\ ${ }^{1}$ China Institute of Water Resources and Hydropower Research, Chegongzhuang west street No. 20, \\ Nisha Dong Room 111, Haidian District, Beijing, China, 100048. \\ abing.liu@okstate.edu, b22859325@qq.com, 'zxmwq@126.com, dzhaoyang1224@163.com, \\ e308352519@qq.com, ${ }^{7} 75335114 @ q q . c o m$
}

Keywords: infiltration rate (IR); organic matter (OM); root system; soil erosion, vegetation species.

Abstract. Soil erosion has been a severe environmental problem all over the world. Vegetation significantly affects soil properties, organic matter, infiltration, runoff, and soil organisms which further influence soil erosion. Canopy and roots are the main two parts that vegetation affects soil erosion. Canopy and roots can increase the infiltration rate, reduce runoff, increase soil organic matter, and then reduce soil erosion. However, how root affects soil erosion and hydrology system has not been fully understood. The roots create water channels, improve soil structure, hold soil, and on the other hand, it can decrease the infiltration rate by taking up macropores, increase bulk density. This study analyzes the results from previous researches, summaries the effects of vegetation roots (fine roots and taproots system) on infiltration, organic matter, bulk density, and further talks about how roots affect soil erosion directly and indirectly.

\section{Introduction}

Soil erosion has been a cruel environmental problem since 1930s [1]. Soil erosion can destroy soil structure, reduce soil quality, and further affects food produce. Soil erosion can also cause non-point pollution, block stream, and other environmental problems. So soil erosion study is crucial to solve those problems. Vegetation is a key factor to study soil erosion and conservation. Vegetation has two main effects on infiltration: the canopies reduce the speed of rainfall and the roots increase the channels in the soil [2]. Both of them can increase infiltration $[3,4]$.

Research about how vegetation affects soil erosion is mainly focus on canopy. Dunne et al. [3] reported that infiltration decreased with the distance to the tree (Paloverde and Creosote) increased. The researchers studied the effect of only canopies on IR and they inferred that tree canopies can help increase IR. The main effect of tree canopies is rainfall interception. First, the canopies reduce the kinetic energy of the raindrop [5] and secondly, by intercepting the rainfall, the canopies give the water more time to infiltrate into soil [6]. However, root system is also important for hydrology circle and soil erosion study. It is found that roots can also affect soil erosion by influencing IR and soil erodibility [7].

Infiltration is a significant factor for hydrologic study and soil erosion [8]. With the same vegetation, the interception and evapotranspiration (ET) for a certain rainfall event is constant. So when more water infiltrates into the soil, there would be less runoff water and reduced soil erosion, slow down 
stream flow and decreased flooding. However, Bharati et al. [9] indicated that high dense living roots might decrease the water infiltration in soil for the reason that roots hairs would block the small holes in the soil. Infiltration is affected by rainfall density, soil structure, vegetation, and topography. Wei et al. [10] found that higher antecedent soil moisture can reduce runoff and soil loss significantly. Trees because of their deeper roots, they have been reported that have higher ET which will reduce soil moisture [11]. Baets et al. [12] compared the effects of tap and fine-branched roots on soil erosion, and reported that fine-branched roots could reduce soil erosion more than tap roots.

Roots affect soil erodibility mainly by influencing soil OM, which has significant impact on soil erodibility. Roots can also reduce by increasing soil resistance. Smith [13] tested how much vegetation roots can effect bank erosion. His results indicated that bank has 20,000 times more resistance to erosion where it has 16 to 18 percent by volume of roots with a $5-\mathrm{cm}$ root-mat. Thus, the impacts of roots on soil erosion have not been considered in the mainstream soil erosion models like Universal Soil Loss Equation (USLE) and Soil and Water Assessment Tool (SWAT). The influences of roots on soil erosion are really complicated and the principles have not been fully understood [14].

The objective of this study is to review the previous works which were about how roots affect infiltration by influencing macropores, bulk density and OM; and how the roots types and structures affect soil erosion rates. I also reviewed how roots affect the prediction of soil erosion models. The following hypothesizes are given: (1) if macropores can increase IR depends on the root types; (2) roots increase OM which increases IR and reduces soil erosion; (3) root types have different impacts on bulk density change; and (4) soil erosion rate is negatively related to root characters; (5) soil erosion models include the effects of roots can better predict soil erosion rates.

\section{Roots' effects on infiltration rate}

Tree root system may affect IR in different ways. Roots affect IR by creating macropores in the soil, affecting bulk density and OM. In the following section, I will review how roots affect the three parts respectively.

Macropores. Macropores increase infiltration by increasing the flow rate within the soil and enhancing soil storage [15]. Roots grow or move through cracks. After roots decayed, the space was left to become macropores. Lamandé et al. [16] indicated that the tree roots decaying can create high density of macropores in the soil C-horizon. It was also found that macropore sheath extents were 1.0-2.2 mm when there were roots while no macropores sheath when no roots existed [17]. Lesturgez et al. [18] tested how the roots of a pasture species (Stylosanthes hamata) affect the number of macropores after deforestation. Their results showed that after 2-year grown, the Stylosanthes hamata developed large amount of roots. As a consequence, the decay of the roots generated quite a number of macropores. Devitt and Smith [19] compared the water flow through soil between plots with roots and without roots. Their results indicated that with roots there was more water flowed into the soil and could reach deeper. They also showed that with more roots there would be more macropores and more water infiltrated. David [20] studied the IR change along the distances (0 to 4 meters) from stem to interspace. The average canopy diameter of their studied vegetation (chenopod shrubs -Atriplex vesicaria, the bladder saltbush - and various bluebushes - Maireana sedifolia, the pearl bluebush, and M. pyramidata, the black bluebush) was $92.2 \mathrm{~cm}$ (S.D. $33.9 \mathrm{~cm}$ ). Their results indicated that even out of canopy, the IR still decreases when away from the stem. This is due to the reason that the macropores which are related to roots growth and decay also decrease from stem to the interspace [21]. 
However, different kinds of roots and roots in different growing seasons may have different effects on macropores. Mitchell et al. [22] indicated that fibrous roots (like wheat) may not have macropores while taproot system (like alfalfa) can have stable macropores after roots decay and that increases IR. Bharati et al. [9] argued that the IR of switchgrass (Panicum virgatum) reduced in August may due to the high density of living roots in August which would take up the already existing macropores. That is the amount of macropores would reduce, as a result, the IR would decrease. However, the authors did not do any experiments to test their explanations. Tree density can also affect IR. Mishra and Sharma [23] compared the IR of Prosopis juliflora, Dalbergia sissoo and Eucalyptus tereticornis to the bare soil. This study did experiments on the same Aquic Petrocalcic Natrustalf soil. Due to the same soil type and the same bare soil control treatment of these studies, it is possible to analyze the trees effects and the differences among tree species. From the results it could seen that trees can increase IR. The Prosopis juliflora increased the IR most, and Dalbergia sissoo has higher IR than Eucalyptus tereticornis. Zapata-Sierra and Manzano-Agugliaro [24] studied six tree species' effects on infiltration, and got the similar results as Mishra and Sharma [23]. They also showed that the maximum IR occurred when the tree density was about 100 trees $\mathrm{ha}^{-1}$, and when the tree height was 15 to $20 \mathrm{~m}$. The above two research can be explained that tree canopy and roots density decrease as the distance to the stem increases, and the effects of tree canopy and roots will be reduced, as a result the IR falls. The relationship between maximum IR and tree density is due to two reasons: first, if the density is too small, there would be bare soil or soil which is not influenced by trees; secondly, if the density is too high, the tree roots would take up too many of the macropores and reduce IR.

Roots can improve the macropores by creating habitats for earthworms. Bharati et al. [9] analyzed how different land uses - multispecies riparian buffer (MRB), cultivated fields and continuously grazed pasture - affected infiltration along Bear Creek in Iowa. The results showed that MRB had the largest infiltration rate. Within the three types of MRB, the infiltration of silver maple was the greatest, switchgrass' was the smallest and grass filter's was in-between. In this study, the authors realized a large number of earthworms living under the silver maple could contribute to the increasing IR. Yet, when Mitchell et al. [22] studied the roots of alfalfa (Medicago sativa, L.) and wheat (Triticum turgidum, L.), they found that the earthworm channels are unstable for keeping IR stable for a long time.

For the previous research it can be inferred that roots affect macropores dependent on root density, the root types and growing seasons: roots increase macropores with the increase of root density which will increase IR. However, if the roots are growing, or density is too high, or there are too many hair roots, the roots would block macropores which reduces IR.

Bulk density. Effect of roots on bulk density is mainly decided by the diameter of roots. Fine roots which are less than $1 \mathrm{~mm}$ can decrease the bulk density. By contraries, larger roots would increase bulk density by pushing soil while taking up pores [25]. Meek et al. [26] evaluated the effects of alfalfa (Medicago sativa L.) on IR and bulk density. They found that an increase in bulk density form 1.6 to $1.8 \mathrm{Mg} \cdot \mathrm{m}^{-3}$ could decrease IR by $53 \%$. They also found that Alfalfa roots increased the IR and decreased the bulk density. Their research showed that although there was earthworm activity under the vegetation which would influence the result, they inferred that the earthworm activity could not contribute as much as the root system. In David [20] also found that the bulk density was lower under the canopy, which would be one of the reasons that IR was higher under the canopy. 
However, Meek et al. [26] reported that bulk density change is not related to water flow in the macropores. When Keller and Håkansson [27] examined the relationships between bulk density, soil particles and OM, they found that the OM largely controlled the bulk density. Organic matter had a significant negative influence on bulk density. This could mean that the effects of bulk density on IR reflects the OM directly, which is affected by canopy, roots, litters, etc. The same relationship was also found by another research [27]. It is essential to evaluate the effect of root on OM for better understanding of the effect of roots on bulk density and IR.

Organic matter (OM). Organic matter has a positive relationship with IR. Jimenez et al. [28] studied the IR of pine and green forest in Tenerife, Spain. They compared the infiltration rates under site 1 mountain-top "white broom" vegetation (Spartocytisus supranubius), site 2 Canarian pine (Pinus canariensis), site 3 mixture of pine and green forest (Erica scoparia, Erica arborea, Myrica faya, Laurus azorica, and other species), site 4 pine groves (Pinus canariensis), and site 5 green forest. From the infiltration rates it can seen that the green forest had the highest IR and the Spartocytisus supranubius had the lowest IR. The reason for this phenomenon was the green forest had the highest OM while Spartocytisus supranubius had the lowest. The authors assessed relationships between the infiltration rate and soil factors, and found that IR had a strong positive relationship with OM $\left(r^{2}=0.9\right)$. Moffet et al. [5] studied the effects of biosolids on infiltration and steady-state infiltration rate, and indicated that increasing biosolids will increase final infiltration rate and cumulative infiltration.

Vegetation can increase organic matter in soil [3,29], so that the influence of organic matter on IR could indicate the effects of different tree species on IR - the more organic matter a tree species can adding to the soil, the more it can increase the IR. Moreover, Dalbergia sissoo has long taproots and numerous surface roots and the Dalbergia sissoo has highest organic carbon, this could be the reason why Dalbergia sissoo has higher IR than Eucalyptus tereticornis. Prosopis juliflora increases the organic carbon less than Dalbergia sissoo, however the Prosopis juliflora has largest and deepest root system, and this could be the reason that Prosopis juliflora has the highest IR. Lange et al. [30] studied the roots of three tree species - Norway spruce (Picea abies (L.) Karst), silver fir (Abies Alba Miller) and European beach (Fagus sylvatica L.) - and their relationship with IR. They found that root length was a crucial factor for infiltration. These findings indicated that roots not only can increase IR by adding organic matter, but the root length also can affect IR directly. Nonetheless, Lange et al. [30] only presented that root length was a "crucial factor" for IR, but they did not show how root length influences the IR.

From the above we can see that roots can influence the OM in the soil. Although roots channel may provide the environment to increase the decomposition of OM, overall, the roots decay increases the total OM. This may also affect the bulk density and IR, because bulk density has a negative relationship with OM. On the other hand, increased OM can increase the water infiltrates into the soil. Taproot system may have higher impact on increasing OM in soil than the fibrous roots.

One question arises after the review about bulk density and OM. From the results of Keller and Håkansson [27] and Meek et al. [26], if increase OM, the bulk density will decrease, which increase IR, and then decrease erosion. However, from Jepsen's [31] results, decrease bulk density resulted in increasing erosion. Moreover, fine roots decrease bulk density but they reduce erosion more than taproots [14]. This study showed that fine roots can hold soil particles together much more than taproots. One possible explanation to these phenomena would be that: the most efficient way roots reducing erosion would be holding soil particles then increasing soil resistance to erosion. This effect 
of increasing resistance may be much stronger than other impacts; as a result, the roots show a reduction of erosion as a whole.

\section{Roots' effects on soil erosion}

Gyssels et al. [29] analyzed the roots' effects on controlling soil erosion by water. They showed that plant roots could reduce soil erosion by increasing the OM in soil. The research of Baets et al. [32] shows that plant roots could also reduce water erosion rates. The experimental groups were grass (fine-branched roots), carrots (tap roots) and carrots with fine-branched weeds on both sandy loam soil and silt loam soil and the control groups were bare plots on the two above soils. Total mean bottom shear stress, and hydraulic radius were calculated during the hydraulic flume experiments. Soil detachment rate, root density, root length density and coefficients of determination $\left(\mathrm{R}^{2}\right)$ for each exponential were calculated by certain formulas. The results indicated that root density had a negative exponential relationship with soil detachment rate. It showed that grasses roots could reduce water erosion better than carrots' in the early growth stages and the root length density had negative exponential relationship with soil detachment rate on silt loam soil but had no such relationship on sandy loam soil. It can also be indicated that when density increased, the effect of root density on reducing erosion decreased and the thicker roots reduced the water erosion less compared to fine roots. This article gave a formula to calculate the erosion-reducing effect using the fine and thick roots. The authors further reported that silt loam soil was more resistant to erosion than sandy loam soil. Roots could reduce more erosion when soil was wet than it was dry, and the carrot soil detachment rate values increased with flow shear stress but the ability of reducing erosion of grasses roots have no relationship with flow shear stress. Moffet et al. [5] studied the effects of biosolids on infiltration and steady-state infiltration rate; and the difference of infiltration and steady-state infiltration rates between vegetated soil and bare soil. In this study, infiltration and soil loss data were collected in 380 plots in Chihuahuan Desert, TX. Through the experiments, the following conclusions were gained: increasing biosolids will increase final infiltration rate and cumulative infiltration, and reduce soil erosion. The main possible reasons why increasing biosolids leads to the above results were: it could enhance ground cover, soil organic carbon content and hydraulic conductivity of the surface crust. Other studies also showed that fine roots reduced soil erosion more than taproots system [33,7].

Zhou and Shangguan [14] studied how the shoot and roots of perennial ryegrass (Lolium perenne L.) affect soil erosion separately. They grew the ryegrass for 27 weeks. Before the $27^{\text {th }}$ week, canopy contributed over $50 \%$ for reducing runoff and $44 \%$ in the $27^{\text {th }}$ week. In contrast, the roots contributed more than $90 \%$ for decreasing sediment yield especially in the late time. The authors indicated that soil erosion rate is positively significant related to fine roots, root length density, and root biomass density. It was also mentioned the root system also increased the soil physical properties, like soil strength, shear strength and etc. which lead to decrease soil erosion. De Baets et al. [32] showed that the relative soil detachment rate has an exponentially decreasing relationship with root density, root length density and root area ratio, respectively. Moreover, they found that root density has effect on soil detachment rate when root density is between $0-4 \mathrm{~kg} \cdot \mathrm{m}^{-3}$, and when root density is higher than $4 \mathrm{~kg} \cdot \mathrm{m}^{-3}$ it would not additionally decrease soil erosion significantly. Similar to root density, the most active root length density is in the range of 0 to $500 \mathrm{~kg} \cdot \mathrm{m}^{-3}$. They also indicated that when soil cross-sectional occupation by roots ranged from 0 to $10 \%$, the erosion rates decreased to alsmost zero, while the erosion rates only reduced $25 \%$ to $50 \%$ for the same increase in vegetation cover. In this study, four kinds of vegetation 
species were compared about their roots' effect on erosion rates. The roots of soybean, corn and barley may be more effective than grass roots, however the root length density is much higher for grass roots than soybean and corn. Nevertheless, the four different species were not tested on the same soil, so the results may not reflect the real efficiency of the four kinds of roots. Besides, their research also indicated that the roots have the ability to hold soil particles and increase the roughness, which also helps reduce soil erosion.

Roots also affect soil erosion indirectly by influencing IR, OM and bulk density. Jepsen et al. [31] tested the relationship between sediment erosion and shear stress and bulk density and showed that the sediment erosion rate increased when bulk density decreased. They developed the equation that the sediment erosion rate is equal to $\mathrm{Al}^{\mathrm{n}} \rho^{\mathrm{m}}$. Where $\mathrm{l}$ is the shear stress, $\rho$ is the bulk density, and $\mathrm{n}, \mathrm{m}$, and $\mathrm{A}$ are constants. Increased $\mathrm{OM}$ due to roots can increase soil erodibility directly, which reduces soil erosion rate. Soil erodibility $\left(\mathrm{K}, \mathrm{t} \cdot \mathrm{h} \cdot \mathrm{MJ}^{-1} \cdot \mathrm{mm}^{-1}\right)$ is mostly calculated by the equation created by Wischmeier and Johnson [34]. Using the data from Zhou and Shangguan [14], I calculated the K change with the change of $\mathrm{OM}$. When $\mathrm{OM}$ changes from $1.43-1.52 \%$, the $\mathrm{K}$ changed from $0.0539-$ $0.0535 \mathrm{t} \cdot \mathrm{h} / \mathrm{MJ} \cdot \mathrm{mm}$, which means the soil erosion rate reduced directly by $0.7 \%$.

\section{Soil erosion models with the influence of the roots}

Gyssels et al. [29] summarized the roots effects on different soil erosion process based on Water Erosion Prediction Project (WEPP). Their results inferred that canopy can better protect soil from erosion when it is splash and interrill erosion. When it is rill and gully erosion, roots' effect on reducing erosion is larger than canopy. Gyssels and Poesen [29] discussted the impacts of shoot and roots on erosion depending on the plant growth stages. They concluded that in the early growing stages when the coverage of shoot is small, roots are more importance in decreasing erosion by concentrated flow. When the canopy is plentiful, it takes over the effects of the roots in reducing soil erosion. After the crops are harvested or defoliated, there would be no protection from canopy, therefor the dead roots that remain in the upper soil layer will provide extra resistance to the soil until the planted canopy grow back.

The two soil erosion models that consider roots influence on soil erosion are Revised Universal Soil Loss Equation (RUSLE) and WEPP. In the RUSLE, two out of five subfactors of the $\mathrm{C}$ factor (cover management factor) have the effects of roots. They use the root mass to help calculate the rill and interrill erosion at the plot scale. The two factors are prior land use subfactor (PLU) and soil surface-roughness subfactor (SR). PLU is the amounts of roots and subsurface residue of the harvested crops are used to calculate the impact on interrill and rill erosion rates. SR is corrected for tillage operation (Rt) and for subsurface biomass density present in the top $10 \mathrm{~cm}$ soil. WEPP uses root densities to validate the plant growth and residue decomposition component. Living and dead roots in the top soil are used for adjustment of rill and interrill erodibility parameters for cropland soils. For rangeland soils only rill erodibility and not interrill erodibility is adapted [35]. Baets et al. [12] indicated that the observed soil erosion rate was better predicted with the RUSLE model and the WEPP model for croplands. And RUSLE can predict erosion rates for rangelands better than with the WEPP model. This indicates that the roots impacts can improve the ability of soil erosion models to estimate erosion rate. 


\section{Conclusion}

After reviewing the previous studies, it can be deduced that vegetation roots can affect IR and soil erosion rates significantly. Roots influence IR and erosion rates by changing macropores, bulk density, OM, soil properties, and organism (earthworms) that are living in the soil. Roots' decay can also provide channels in the soil to increase water flow into and within the soil. The root density, root length density and root area have negative exponential relationship with soil erosion rates.

However, the impacts are complicated. Roots increase macropores, but fine roots or high root density may take up macropores and reduce IR. Fine roots decrease bulk density and increase IR and erosion rates, on the contraries, taproots have the opposite impacts on bulk density. The channels created by roots may increase the decomposition of OM, while dead roots add OM into the soil. Over all, roots increase the total OM in the soil. Some studies found that the taproots may increase OM more than fine roots. This indicates that taproots can decrease bulk density and increase IR more than fine roots. Roots can improve the soil properties and enhance the soil resistance to erosion. Most research inferred that fine roots can hold more soil than taproots and make soil more resistance to erosion. Naturally, roots provide habitats for organisms, especially earthworms, which can affect soil properties, soil structures and other factors that have impacts on soil hydrology or soil erosion. Although some research found that the earthworm may not change much or have significant influences on IR or erosion. Soil erosion models which consider the impacts of roots can better predict soil erosion rates than those which do not.

\section{Acknowledgements}

This project was partially supported by the Open Research Fund of State Key Lab of Simulation and Regulation of Water Cycle in River Basin (ZY1304) 、 the National Science Foundation of China (51379008), and the Project Sponsored by the Scientific Research Foundation for the Returned Overseas Chinese Scholars, State Education Ministry.

\section{Reference}

[1] E.P. Eckholm, Losing ground, Pergamon Press, Oxford, 1976.

[2] A.R. Jarrett, J.R. Hoover, Evaluating the effect of increased concentrations of co 2 on infiltration rate. Transactions of the ASAE - American Society of Agricultural Engineers, 28 (1985) 179-182.

[3] T. Dunne, W.H .Zhang, B.F. Aubry, Effects of rainfall, vegetation, and microtopography on infiltration and runoff. Water Resources Research, 27 (1991) 2271-2285.

[4] J.M. Tromble, K.G. Renard, A.P. Thatcher, Infiltration for three rangeland soil-vegetation complexes. Journal of Range Management, 27 (1974) 318-321.

[5] C.A. Moffet, R.E. Zartman, D.B. Wester, R.E. Sosebee, Surface biosolids application: Effects on infiltration, erosion, and soil organic carbon in chihuahuan desert grasslands and shrublands. Journal of Environmental Quality, 34 (2005) 299-311.

[6] A.R. Aston, (1979). Rainfall interception by eight small trees. Journal of Hydrology, 42 (1979) 383-396.

[7] Y. Li, X. Zhu, J. Tian, Effectiveness of plant roots to increase the anti-scourability of soil on the loess plateau. Chinese Science Bulletin, 36 (1991) 2077 - 2082. 
[8] G.W. Hamilton, D.V. Waddington, Infiltration rates on residential lawns in central pennsylvania. Journal of Soil and Water Conservation, 54 (1999) 564-568.

[9] L. Bharati, K.H. Lee, T.M. Isenhart, R.C. Schultz, Soil-water infiltration under crops, pasture, and established riparian buffer in midwestern USA. Agroforestry Systems, 56 (2002) 249-257.

[10] L. Wei, B. Zhang, M. Wang, Effects of antecedent soil moisture on runoff and soil erosion in alley cropping systems. Agricultural Water Management, 94 (2007) 54-62.

[11] I.R. Calder, Forests and water-ensuring forest benefits outweigh water costs. Forest Ecology and Management, 251 (2007) 110-120.

[12] S.D. Baets, J. Poesen, A. Knapen, P. Galindo, Impact of root architecture on the erosion-reducing potential of roots during concentrated flow. Earth Surface Processes and Landforms, 32 (207) 1323-1345.

[13] D.G. Smith, Effect of vegetation on lateral migration of anastomosed channels of a glacier meltwater river. Geological Society of America Bulletin, 87 (1976) 857.

[14] Z.C. Zhou, Z.P. Shangguan, The effects of ryegrass roots and shoots on loess erosion under simulated rainfall. Catena, 70 (2007) 350-355.

[15] R.F. Cullum, Macropore flow estimations under no-till and till systems. Catena, 78 (2009) 87-91.

[16] M. Lamandé, R. Labouriau, M. Holmstrup, S.B. Torp, M.H. Greve, G. Heckrath, . . . O.H. Jacobsen, Density of macropores as related to soil and earthworm community parameters in cultivated grasslands. Geoderma, 162 (2011) 319-326.

[17] J.B. Stewart, C.J. Moran, J.T. Wood, Macropore sheath: Quantification of plant root and soil macropore association. Plant and Soil, 211 (1999) 59-67.

[18] G. Lesturgez, R. Poss, C. Hartmann, E. Bourdon, A. Noble, S. Ratana-Anupap, Roots of stylosanthes hamata create macropores in the compact layer of a sandy soil. Plant and Soil, 260 (2004) 101-109.

[19] D.A. Devitt, S.D. Smith, Root channel macropores enhance downward movement of water in a mojave desert ecosystem. Journal of Arid Environments, 50 (2002) 99.

[20] D. David, Hydrologic effects of dryland shrubs: Defining the spatial extent of modified soil water uptake rates at an australian desert site. Journal of Arid Environments, 45 (2000) 159-172.

[21] J. Brisson, J.F. Reynolds, The effect of neighbors on root distribution in a creosotebush (larrea-tridentata) population. Ecology, 75 (1994) 1693-1702.

[22] A.R. Mitchell, T.R. Ellsworth, B.D. Meek, Effect of root systems on preferential flow in swelling soil. Communications in Soil Science and Plant Analysis, 26 (1995) 2655-2666.

[23] A. Mishra, S.D. Sharma, Influence of forest tree species on reclamation of semiarid sodic soils. Soil Use and Management, 26 (2010) 445-454.

[24] A. Zapata-Sierra, F. Manzano-Agugliaro, Influence of six tree species on water infiltration in soil. Agrociencia, 42 (2008) 835-845.

[25] G. Gyssels, J. Poesen, E. Bochet, Y. Li, Impact of plant roots on the resistance of soils to erosion by water: A review. Progress in Physical Geography, 29 (2005) 189-217.

[26] B.D. Meek, E.R. Rechel, L.M. Carter, W.R. DeTar, A.L. Urie, Infiltration rate of a sandy loam soil: Effects of traffic, tillage, and plant roots. Soil Science Society of America Journal, 56 (1992) 908-913.

[27] T. Keller, I. Håkansson, Estimation of reference bulk density from soil particle size distribution and soil organic matter content. Geoderma, 154 (2010) 398-406. 
[28] C.C. Jimenez, M. Tejedor, G. Morillas, J. Neris, Infiltration rate in andisols: Effect of changes in vegetation cover (tenerife, spain). Journal of Soil and Water Conservation, 61 (2006) 153-158.

[29] G. Gyssels, J. Poesen, The importance of plant root characteristics in controlling concentrated flow erosion rates. Earth Surface Processes and Landforms, 28 (2003) 371-384.

[30] B. Lange, P. Lüescher, P.F. Germann, Significance of tree roots for preferential infiltration in stagnic soils. Hydrology and Earth System Sciences, 13 (2009) 1809-1821.

[31] R. Jepsen, J. Roberts, W. Lick, Effects of bulk density on sediment erosion rates. Water, Air, \& Soil Pollution, 99 (1997) 21-31.

[32] S. De Baets, J. Poesen, G. Gyssels, A. Knapen, Effects of grass roots on the erodibility of topsoils during concentrated flow. Geomorphology, 76 (2006) 54-67.

[33] J. Kort, M. Collins, D. Ditsch, A review of soil erosion potential associated with biomass crops. Biomass and Bioenergy, 14 (1998) 351-359.

[34] W.H. Wischmeier, C.B. Johnson, A soil erodibility nomograph for farmland and construction sites. Soil and Water Conservation, 26 ( 1971 ) 189-193.

[35] K.G. Renard, G.R. Foster, G.A. Weesies, D.K. McCool, D.C. Yoder, Predicting soil erosion by water: A guide to conservation planning with the revised universal soil loss equation (rusle). Agriculture Handbook (703), WashingtonD.C., 1997. 